\title{
Regulation of Lipoprotein Lipase Immunoreactive Mass in Isolated Human Adipocytes
}

\author{
Philip A. Kern, John M. Ong, John W. F. Goers, * and Mary E. Pedersen* \\ Department of Medicine, Cedars-Sinai Medical Center, Los Angeles, California 90048; and *Department of Chemistry, \\ California Polytechnic State University, San Luis Obispo, California 93407
}

\begin{abstract}
Previous studies of human adipose tissue lipoprotein lipase (LPL) have focused on enzyme catalytic activity, and have not measured the LPL protein directly. To study the regulation of the LPL protein, an antibody against purified bovine LPL was used. To demonstrate the specificity of the antiserum, adipose homogenates were Western blotted, and adipocytes were radiolabeled and the cell homogenates immunoprecipitated, yielding a single specific band at $53 \mathrm{kD}$. Breakdown products of LPL were demonstrated at 35 and $20 \mathrm{kD}$ by Western blotting.
\end{abstract}

An ELISA for human adipose LPL was established, in which LPL was sandwiched between affinity-purified antibody and biotinylated affinity-purified antibody. The standard curves for bovine LPL and human adipose LPL were parallel, and LPL activity correlated strongly with LPL immunoreactive mass. Thus, the bovine LPL standard curve was used to estimate LPL immunoreactive mass from human adipose tissue.

The regulation of LPL activity and immunoreactive mass were compared in cultured adipocytes in the presence an absence of insulinlike growth factor-I/somatomedin C (IGF-I), insulin, and fetal bovine serum. IGF-I and a high insulin concentration (70 $\mathrm{nM}$ ) stimulated only the heparin-releasable (HR) component of LPL activity and immunoreactive mass, and neither IGF-I nor insulin affected LPL specific activity. In contrast, $10 \%$ fetal bovine serum stimulated $H R$ activity, HR mass, and cellular extractable (EXT) immunoreactive mass, with no effect on EXT activity. This resulted in a decrease in EXT specific activity in response to serum. The effects of the locally produced nucleosides adenosine and inosine were studied in a similar manner. As with serum, adenosine stimulated HR activity, HR mass, and EXT immunoreactive mass, resulting in a decrease in EXT specific activity. Inosine stimulated an increase in HR activity and HR mass, but had no effect on EXT, and thus did not change LPL specific activity.

Thus, a sensitive ELISA for adipose tissue LPL has been developed using a specific, well-characterized antibody. Regulation of human LPL immunoreactive mass was demonstrated

Portions of this study were presented at the national meeting of the American Federation for Clinical Research, May 1987.

Address reprint requests to Dr. Kern, Division of Endocrinology, Room 1735, Cedars-Sinai Medical Center, 8700 Beverly Blvd., Los Angeles, CA 90048.

Received for publication 18 May 1987 and in revised form 14 September 1987.

J. Clin. Invest.

(C) The American Society for Clinical Investigation, Inc. 0021-9738/88/02/0398/09 \$2.00

Volume 81, February 1988, 398-406 in vitro by IGF-I, serum, high concentrations of insulin, adenosine, and inosine. This method will permit further investigations into the regulation of the LPL protein.

\section{Introduction}

Adipose tissue lipoprotein lipase (LPL) ${ }^{1}$ plays a central role in lipoprotein metabolism, and much effort has been devoted to the study of LPL regulation (1). Previous studies on the regulation of LPL in humans, however, have measured only LPL catalytic activity, and have never directly quantitated the LPL protein. Although LPL has been purified from various sources and antisera to the enzyme have been raised (reviewed in references 1-3), it has generally been difficult to develop a quantitative LPL immunoassay. There are two previous reports of immunoassays that were applicable to human LPL. Olivecrona et al. (4) reported an immunoassay for bovine LPL with an antiserum that cross-reacted with human LPL. Goldberg et al. (5) have recently reported an ELISA for human postheparin plasma LPL using a monoclonal antibody directed aganist human milk LPL. No previous study has reported an immunoassay for human adipose tissue LPL.

Although it has been difficult to measure the LPL protein, the regulation of LPL activity has been the subject of much study. LPL activity in adipose tissue usually correlates with the prevailing plasma insulin level of the subject (6-8). In vitro studies, however, have uncovered important differences between rat and human LPL. Although LPL in rat adipocytes and adipose tissue were responsive to insulin $(9,10)$, human adipocyte and adipose tissue LPL activity was not stimulated by physiologic concentrations of insulin $(11,12)$. Other regulators of LPL activity in human adipocytes are insulinlike growth factor-I/somatomedin C (IGF-I), fetal bovine serum, and glucose $(11,13)$. The nucleoside adenosine, and its metabolite inosine, have well-recognized effects on metabolism in many tissues $(14,15)$. In adipose tissues, adenosine is an important local regulator of lipolysis, and potentiates other insulin-mediated functions (16). Because LPL activity and hormone-sensitive lipase-mediated lipolysis are often inversly regulated (17), adenosine may also be an important regulator of LPL. Whether any of these substances affect the LPL protein, or whether they activate an inactive LPL, has not been directly tested due to the unavailability of an LPL immunoassay.

We report herein an ELISA for human adipose tissue LPL using an affinity-purified polyclonal antiserum raised in chickens against purified bovine LPL. This antibody crossreacts with human LPL and is specific for LPL in adipose

1. Abbreviations used in this paper: EXT, extractable LPL; HR, heparin-releasable LPL; IGF-I, insulinlike growth factor-I/somatomedin C; LPL, lipoprotein lipase; PBSAT, phosphate-buffered saline with $0.1 \%$ bovine serum albumin and $0.1 \%$ Triton X-100; PIA, $\mathrm{N}^{6}$-phenyl-isopropyladenosine. 
tissue homogenates. Furthermore, LPL immunoreactive mass was measured in primary cultures of isolated human adipocytes and regulation by IGF-I, insulin, fetal bovine serum, and adenosine was demonstrated.

\section{Methods}

Adipose tissue and adipocytes. Omental adipose tissue was removed from 31 healthy subjects during elective abdominal surgery. These subjects gave informed consent to the procedure and were between the ages of 24 and $50 \mathrm{yr}$ (mean \pm SEM: $35 \pm 1.5$ ). Mean body mass index was $21.9 \pm 0.54 \mathrm{~kg} / \mathrm{m}^{2}$ (range: $18.2-29.3$ ), and no patient was taking any medication known to affect lipid metabolism. Isolated adipocytes were prepared from fresh adipose tissue as described previously (11). In brief, 2-3-g pieces of fat were minced and digested in flasks containing $10 \mathrm{ml}$ of collagenase II ( $2 \mathrm{mg} / \mathrm{ml}$, Cooper Biochemical, Malvern, PA). The adipocytes that were obtained from the digestion were washed twice in Medium 199 (Gibco, Grand Island, NY) containing 10\% fetal bovine serum (Hyclone, Logan, UT) and twice in serum-free Medium 199. All adipocyte incubations were carried out under sterile conditions at $37^{\circ} \mathrm{C}$ in a $5 \% \mathrm{CO}_{2}$ tissue culture incubator.

LPL catalytic activity. LPL activity was measured against an emulsified $\left[{ }^{14} \mathrm{C}\right]$ triolein substrate, containing human serum as a source of apo CII, as described previously (11). Two fractions from adipose tissue and adipocytes were prepared. The heparin-releasable (HR) fraction was prepared by incubating cells or tissue in PBS containing $13 \mu \mathrm{g} / \mathrm{ml}$ heparin (Fisher Scientific Co., Los Angeles, CA) for $45 \mathrm{~min}$ at $37^{\circ} \mathrm{C}$. The extractable (EXT) fraction was prepared subsequent to the preparation of $\mathrm{HR}$ by disrupting cells or tissue in $0.5 \%$ deoxycholate, $0.02 \% \mathrm{NP}-40,0.73 \%$ sucrose, $0.1 \%$ albumin, $125 \mu \mathrm{g} / \mathrm{ml}$ heparin, and $25 \mathrm{mM}$ Tris, pH 8.3 (18). After separating the lipid cake by centrifugation, the aqueous layer was recovered. An aliquot of each sample was incubated with substrate for $45 \mathrm{~min}$ at $37^{\circ} \mathrm{C}$ and the reaction was then stopped by the addition of Belfrage-Vaughn extraction mixture (19). The liberation of ${ }^{14} \mathrm{C}$-free fatty acids was quantitated and LPL activity was expressed as nanomoles of free fatty acids released per minute per $10^{6}$ cells.

Western blotting. EXT samples of human adipocytes or adipose tissue were prepared as described above for LPL activity except for the absence of albumin in the EXT buffer, and the addition of protease inhibitors to both buffers. The protease inhibitors used were $1 \mathrm{mM}$ PMSF, $1 \mathrm{mM}$ benzamidine, $1 \mathrm{mM}$ EDTA, an $0.05 \mathrm{mM}$ aprotinin. Samples were mixed with an equal volume of cracking buffer $(5 \%$ $\beta$-mercaptoethanol, $2 \%$ SDS, $10 \%$ glycerol, and $0.5 \mathrm{M}$ Tris, pH 6.8) and boiled for $10 \mathrm{~min}$. The samples were then applied to a $5-20 \%$ linear gradient polyacrylamide gel with a $3 \%$ stack, along with prestained molecular weight markers (Bethesda Research Laboratories, Gaithersburg, MD). The separated proteins were then transferred electrophoretically to nitrocellulose (Bio-Rad Laboratories, Richmond, CA) and blotted. Nonspecific binding was blocked by incubating the nitrocellulose in blocking solution (PBS with $5 \%$ bovine serum albumin, $10 \mu \mathrm{g} / \mathrm{ml}$ sheep IgG, $0.1 \%$ Triton X-100) for 2-16 h. The blots were then incubated with primary antibody (chicken antibovine LPL antiserum) for $1 \mathrm{~h}$ at a dilution of $1: 6,000$ in PBS with $0.1 \%$ albumin and $0.1 \%$ Triton X-100 (PBSAT). Two controls were used to demonstrate specificity of the antiserum for LPL: nonimmune chicken serum, and the "flow-through" fraction from the affinity purification of anti-LPL antiserum. This flow-through represents antiserum that has been passed through a bovine LPL-Sepharose column (20), and hence has been depleted of the specific anti-LPL antibodies. After exposure to primary antiserum or control sera, the blots were washed in PBSAT and exposed to a 1:20,000 dilution (in PBSAT) of rabbit anti-chicken antiserum (Sigma Chemical Co., St. Louis, MO) for $1 \mathrm{~h}$. The blots were then washed with PBSAT and incubated for $1 \mathrm{~h}$ with ${ }^{125} \mathrm{I}$-protein A $(200,000 \mathrm{cpm} / \mathrm{ml}$ in PBSAT, Amersham Corp., Arlington Heights, IL). After washing in PBSAT, the blots were air-dried and exposed to x-ray film.
Radiolabeling and immunoprecipitation. Isolated adipocytes were prepared and incubated overnight in Medium 199 containing 10\% fetal bovine serum. Cells were then incubated in methionine-free Medium 199 (Irvine Scientific, Santa Ana, CA) for $2 \mathrm{~h}$ and then labeled with $50 \mu \mathrm{Ci}\left[{ }^{35} \mathrm{~S}\right]$ methionine (ICN Biomedicals, Inc., Irvine, CA) for 30 min at $37^{\circ} \mathrm{C}$. The cells were then immediately placed into lysis buffer (0.1\% SDS, $0.5 \%$ deoxycholate, $1 \%$ Triton X-100, $0.1 \mathrm{M} \mathrm{NaCl}, 5 \mathrm{mM}$ EDTA, $1 \mathrm{mM}$ PMSF, and $10 \mathrm{mM}$ sodium phosphate, $\mathrm{pH} 7.5$ ) and the lipid cake removed after centrifugation. Radiolabeled LPL was then immunoprecipitated from the cell lysate by the addition of $1 \mu \mathrm{g}$ of affinity-purified chicken anti-LPL antibody, followed by the addition of $5 \mu \mathrm{l}$ of rabbit anti-chicken antiserum (Sigma Chemical Co.) and protein A-Sepharose (Pharmacia Fine Chemicals, Piscataway, NJ). After washing the pellets thrice with lysis buffer and twice with $0.5 \mathrm{M}$ $\mathrm{LiCl}, 50 \mathrm{mM}$ Tris, pH 8.0, cracking buffer was added and the immunoprecipitates were analyzed on a $10 \%$ polyacrylamide gel. The gel was fixed, enhanced with sodium salicylate (21), dried, and exposed to x-ray film.

ELISA. The ELISA was performed essentially as described previously for rat LPL (20). Each well of a 96-well microtiter plate (Dynatech Laboratories, Inc., Alexandria, VA) was coated overnight with $200 \mu \mathrm{l}$ of affinity-purified chicken anti-LPL antibody (number 2271, 5 $\mu \mathrm{g} / \mathrm{ml}$ ) in $0.1 \mathrm{M}$ sodium carbonate buffer, $\mathrm{pH}$ 9.3. Samples and bovine LPL standards $(200 \mu \mathrm{l})$ were then added in a buffer containing $1 \mathrm{M}$ $\mathrm{NaCl}, 0.1 \%$ Triton $\mathrm{X}-100,0.1 \%$ albumin, protease inhibitors (PMSF, benzamidine, and aprotinin) and $25 \mathrm{mM}$ Tris, $\mathrm{pH}$ 7.4. The bovine LPL concentrations varied between 100 and $0.78 \mathrm{ng} / \mathrm{ml}$ in serial $1: 2$ dilutions. After incubation for $72 \mathrm{~h}$ at $4^{\circ} \mathrm{C}$, the samples were removed and the wells were washed with PBSAT. Biotinylated affinity-purified chicken anti-LPL antibody (number $2272,0.3 \mu \mathrm{g} / \mathrm{ml}$ in PBSAT) was then added and the plate was again incubated at $4^{\circ} \mathrm{C}$ for $72 \mathrm{~h}$. The wells were again washed, and streptavidin-horseradish peroxidase (Bethesda Research Laboratories, 1:2,000 dilution in PBSAT) was added for $24 \mathrm{~h}$. The wells were then developed for 10-20 min with peroxidase substrate $(1 \mathrm{mg} / \mathrm{ml} \sigma$-phenylenediamine, $0.012 \%$ hydrogen peroxide, in $0.1 \mathrm{M}$ citrate, $\mathrm{pH} 4.5$ ) and read in an ELISA plate reader at $490 \mathrm{~nm}$. By repeated measurements of the same frozen LPL sample, intra- and interassay variation were $5 \%$ and $16 \%$, respectively.

Statistics. All data were expressed as the mean \pm SEM and were analyzed nonparametrically using the Wilcoxon matched-paired signed-rank test.

\section{Results}

The use of this antibody in an ELISA for rat LPL has been demonstrated previously (20). To determine whether this antibody also cross-reacted with human LPL, the inhibition of human LPL catalytic activity was demonstrated (Fig. 1). The HR fraction of isolated human adipocytes was prepared as described under Methods, and incubated with increasing amounts of anti-LPL antiserum. Controls included samples that were incubated in $1 \mathrm{M} \mathrm{NaCl}$, and with nonimmune chicken serum. As shown in Fig. 1, HR was essentially completely inhibited by $1 \mathrm{M} \mathrm{NaCl}$ as well as by the antiserum. Thus, essentially all the lipase activity was LPL and was inhibited by the antiserum.

To demonstrate the specificity of this antibody for LPL, Western blotting was performed. Isolated human adipocytes were homogenized in deoxycholate-heparin buffer (see Methods), and the solublized LPL applied to a polyacrylamide gel, transferred to nitrocellulose, and blotted with anti-LPL antiserum. As shown in Fig. 2 (lane 3), the antiserum identified a band in the adipocyte homogenate that co-migrated with bovine LPL (lane 1 ) at $53 \mathrm{kD}$. To prove that this band represented LPL, the same samples were applied to a gel, transferred 


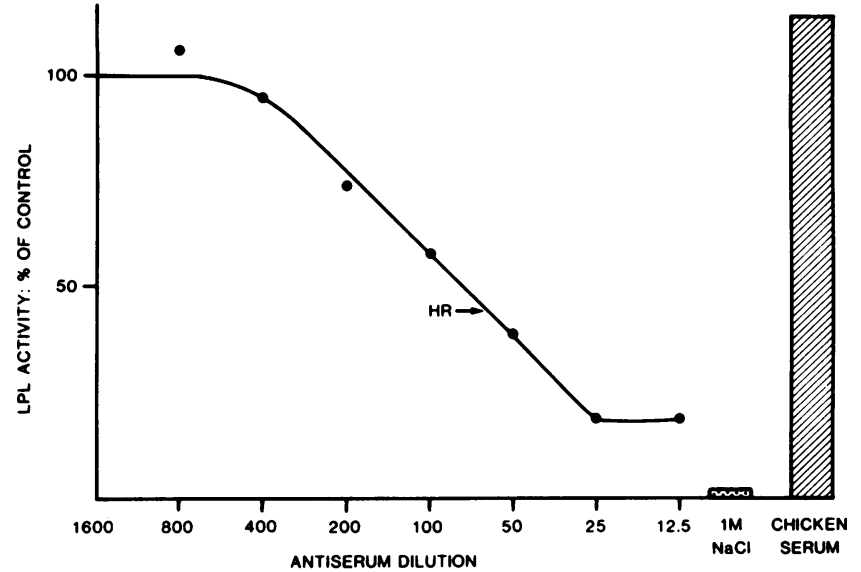

Figure 1. Inhibition of LPL activity by anti-LPL antiserum. The HR fraction from isolated adipocytes was prepared, containing $0.64 \mathrm{neq} /$ min per ml. After $125 \mu \mathrm{l}$ of sample was preincubated with $25 \mu \mathrm{l}$ of the indicated dilution of antiserum for $15 \mathrm{~min}$ at room temperature, the $\left[{ }^{14} \mathrm{C}\right]$ triolein-containing substrate was added and LPL activity was measured as described in Methods. Adipocyte samples were also incubated with nonimmune chicken serum and were made $1 \mathrm{M}$ with $\mathrm{NaCl}$. Data are from one representative experiment out of three.

to nitrocellulose, but blotted with the flow-through from the affinity purification step. As described previously (20), this antibody has been affinity purified by passing the antiserum through a bovine LPL-Sepharose column. Thus, the flowthrough represented antiserum that has been depleted specifcally of the anti-LPL antibodies. When bovine LPL and human adipocyte extract were blotted with the flow-through, the bands at $53 \mathrm{kD}$ were not present (Fig. 2, lanes 2 and 4 for bovine LPL and human adipocytes, respectively). Thus, these data strongly suggest that the $53-\mathrm{kD}$ protein in human adipocytes represented LPL and was specifically recognized by the antibody.

To demonstrate the specificity of this antibody for newly synthesized LPL, cells were radiolabeled with $\left[{ }^{35} \mathrm{~S}\right]$ methionine for $15 \mathrm{~min}$ and then immunoprecipitated with anti-LPL antibodies. As shown in Fig. 3, immunoprecipitation yielded a radiolabeled band at $53 \mathrm{kD}$. This band was not present when the immunoprecipitation was carried out with nonimmune chicken IgG, or when specific antibody was used in the presence of an excess of unlabeled bovine LPL. Thus, these data

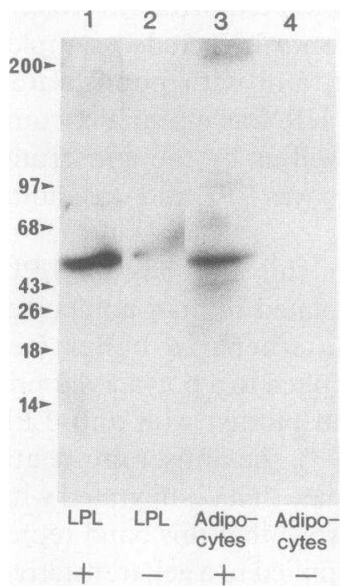

Figure 2. Western blot of human adipocyte LPL. Adipocyte extracts were prepared as described in Methods and applied to a gel (lanes 3 and 4 ) along with purified bovine LPL (lanes 1 and 2). After transferring the separated proteins to nitrocellulose, they were blotted with either anti-LPL antiserum (lanes 1 and 3) or the flowthrough from the affinity purification step (lanes 2 and 4). All blots were then exposed to rabbit anti-chicken antiserum and ${ }^{125} \mathrm{I}$-protein $\mathrm{A}$, as described in Methods.

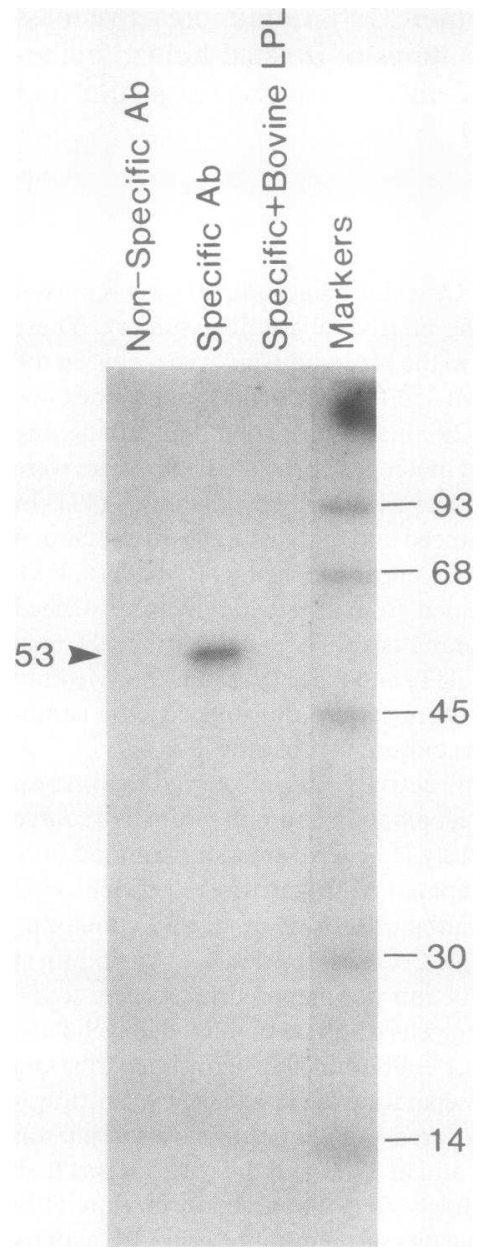

Figure 3. Immunoprecipitation of radiolabeled human adipocyte LPL. Isolated adipocytes were prepared and labeled with 50 $\mu \mathrm{Ci}\left[{ }^{35} \mathrm{~S}\right]$ methionine for 15 $\min$ at $37^{\circ} \mathrm{C}$. The cell extracts were then immunoprecipitated with anti-LPL antibody, followed by rabbit anti-chicken antiserum and protein A-Sepharose (Specific $A b$ ). In the first lane, the immunoprecipitation was performed using nonimmune chicken IgG, and in the third lane, $1 \mu \mathrm{g}$ of unlabeled bovine LPL was added to the cell homogenate to compete with the radiolabeled LPL for the anti-LPL antibodies. The last lane contains ${ }^{14} \mathrm{C}$ labeled molecular mass markers in kilodaltons.

further demonstrate that the 53-kD band from the immunoprecipitation represented LPL.

To demonstrate the presence of LPL breakdown products in human adipose tissue, a sample of human adipose tissue was prepared in the presence and absence of protease inhibitors and then Western blotted. As shown in Fig. 4, when adipose tissue was prepared with protease inhibitors, Western blotting revealed a single band at $53 \mathrm{kD}$ (lane 3) that comigrated with bovine LPL (lane 1 ). When the sample was prepared without protease inhibitors and blotted (lane 4), bands at 35 and $20 \mathrm{kD}$ were identified in addition to the band at 53 $\mathrm{kD}$. When the same samples were blotted with the flowthrough from the affinity purification step (lanes 2 and 5 ), as well as nonimmune chicken serum (lane 6), these bands were not present. Thus, LPL in human adipose tissue tends to break down into smaller peptides when prepared in the absence of protease inhibitors.

An ELISA was developed for human LPL in which LPL was "sandwiched" between two affinity-purified antibodies, one of which was biotinylated (see Methods). As described previously (20), the use of antibodies from two different chickens increased the sensitivity of the assay. In Fig. 5, a standard curve for bovine LPL is shown alongside a dilution curve for human adipose tissue LPL. As can be seen, the standard curve for bovine LPL was parallel to the dilution curve for human adipose LPL. Thus, the immunoreactive mass of bovine LPL was used to quantitate human LPL mass from cell 


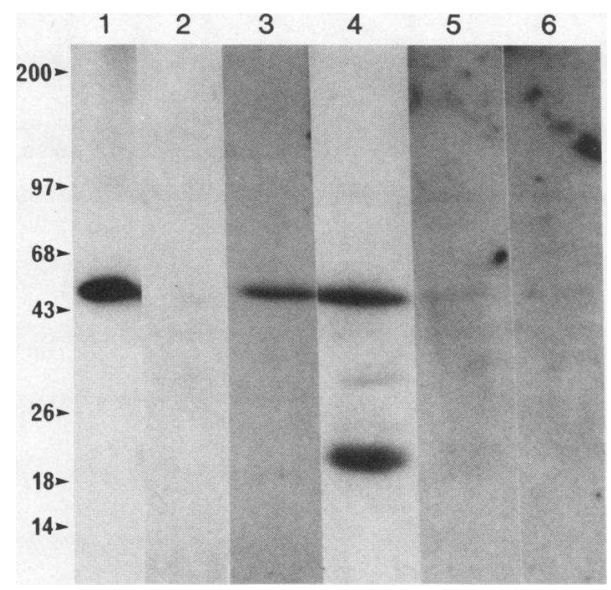

Figure 4. Identification of LPL breakdown products. Samples of purified LPL or adipose tissue extracts were Western blotted as described under Methods. In lanes 1 and 2, bovine LPL was blotted with specific antiserum and the flow-through, respectively. Lanes 3 and 4 contain adipose tissue extracts that were prepared with (lane 3 ) and without (lane 4) protease inhibitors, and then Western blotted with specific anti-LPL. Lanes 5 and 6 contain the same sample as lane 4 (adipose extract without protease inhibitors) but blotted with flow-through (lane 5) and nonimmune chicken serum (lane 6).

and tissue homogenates. To determine whether LPL immunoreactive mass, as estimated from this standard curve, correlated with LPL activity, a sample of adipocyte LPL was serially diluted and assayed for both LPL activity and LPL immunoreactive mass. As shown in Fig. 6, LPL activity correlated strongly with LPL immunoreactive mass using bovine LPL as a standard. Thus, the standard curve for bovine LPL was used to estimate the LPL immunoreactive mass of human adipose tissue samples.

Previous studies have described the regulation of adipocyte LPL activity by insulin, IGF-I, and fetal bovine serum (11). To

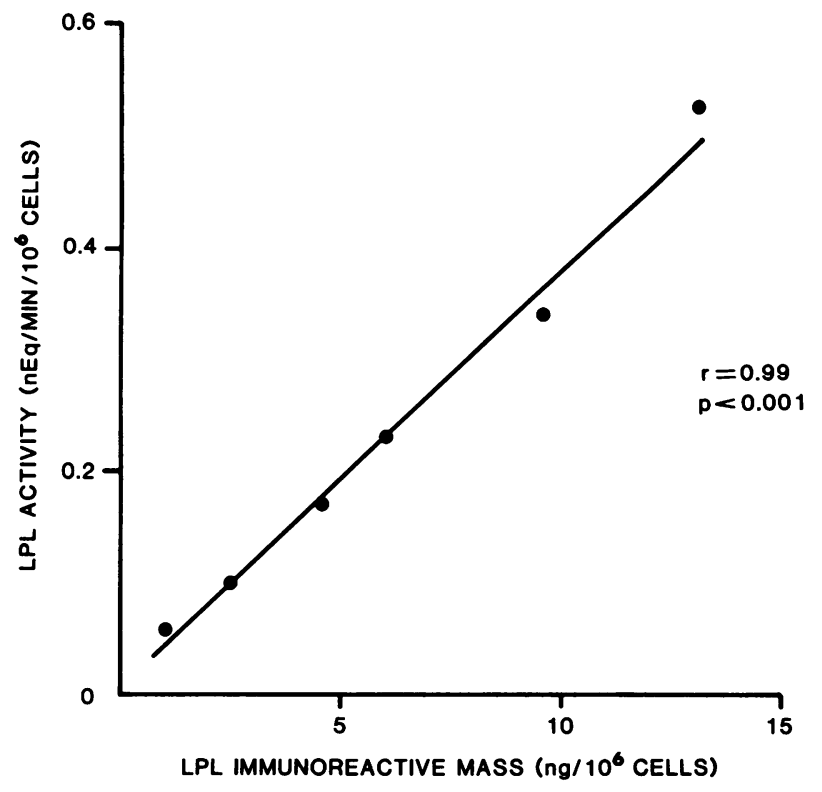

Figure 6. Relationship between LPL activity and LPL immunoreactive mass. LPL was released from a sample of adipose tissue by heparin and this sample was serially diluted. Each dilution was assayed for both LPL activity and LPL immunoreactive mass.

determine whether LPL immunoreactive mass is regulated to the same degree as LPL activity, isolated adipocytes were cultured in medium containing insulin ( $1.8 \mathrm{nM})$, and IGF-I ( 6.5 $\mathrm{nM})$ and LPL activity and mass were measured in the wholecell homogenate. As shown in Fig. 7, IGF-I stimulated LPL immunoreactive mass to the same degree as it stimulated LPL activity. Insulin at a concentration of $1.8 \mathrm{nM}$ had no effect on either LPL activity or mass. Specific activity of the cell homogenates remained constant and was not influenced by IGF-I or insulin.

In addition to studying whole-cell homogenates, the effects

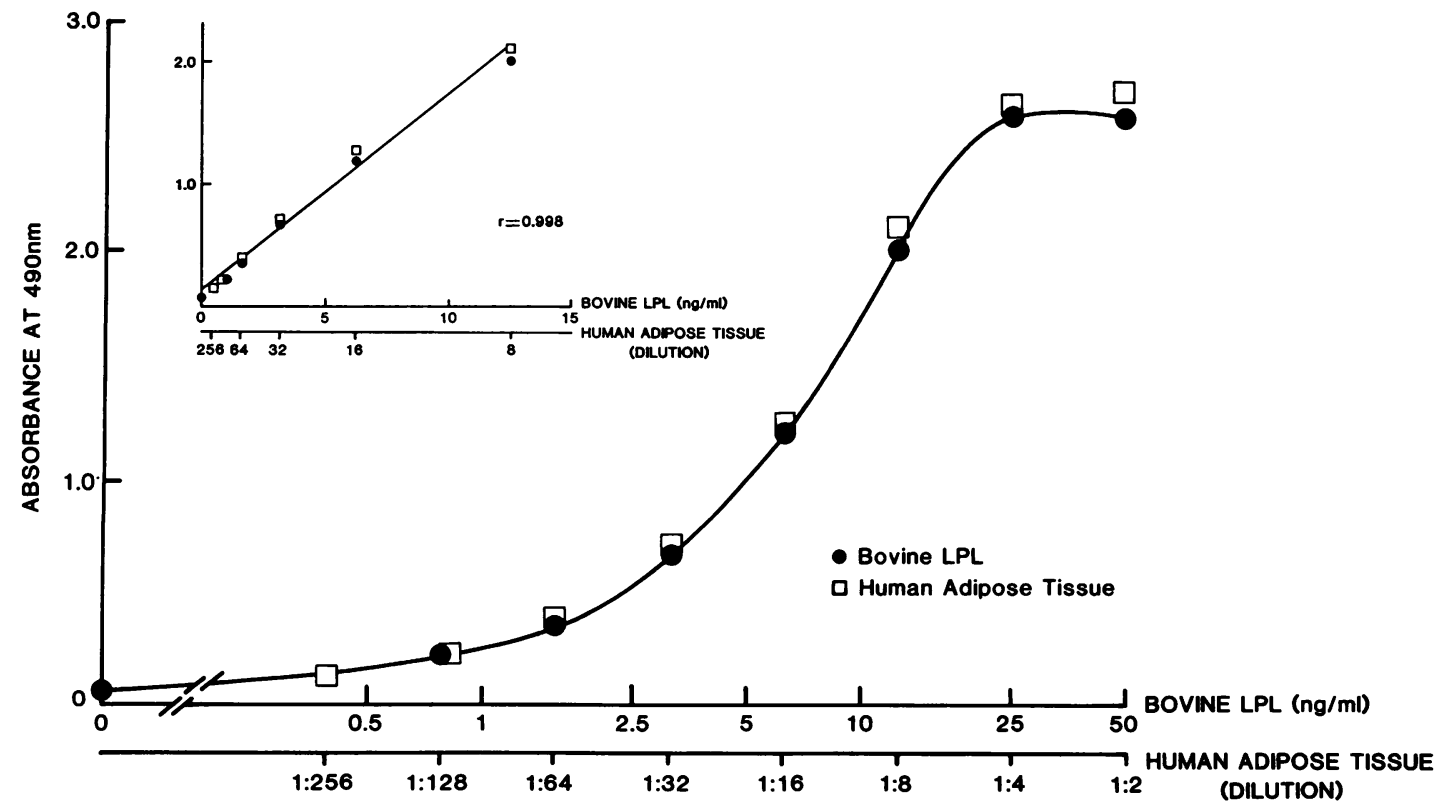

Figure 5. Standard curves for human and bovine LPL. The dilution curve for human adipose tissue extract is shown superimposed on the bovine LPL standard curve from the same assay. (Inset) The working part of the curves is shown without the log scale abscissa. 


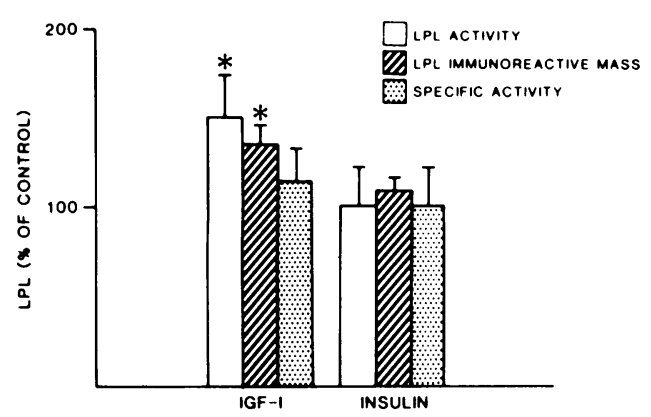

Figure 7. Regulation of LPL activity and immunoreactive mass by IGF-I, and insulin. Isolated adipocytes were incubated for $24 \mathrm{~h}$ in medium containing $6.5 \mathrm{nM}$ IGF-I and $1.8 \mathrm{nM}$ insulin. Total cell LPL activity and immunoreactive mass were measured and expressed as a percentage of control. Control LPL activity, mass, and specific activity were $2.63 \pm 0.63 \mathrm{neq} / \mathrm{min}$ per $10^{6}$ cells, $135 \pm 29$ $\mathrm{ng} / 10^{6}$ cells, and $35.3 \pm 12.5 \mathrm{neq} / \mathrm{min}$ per $\mu \mathrm{g}$, respectively $(n=10)$. Each bar represents $7-12$ experiments. ${ }^{*} P<0.05$ vs. control.

of insulin and IGF-I were studied on the HR and EXT fractions of adipocytes. Previously, we demonstrated that IGF-I stimulated only HR activity, and had no effect on EXT (11). In a similar fashion, a high concentration of insulin $(400 \mathrm{ng} / \mathrm{ml}$ or $70 \mathrm{nM}$ ) stimulated HR but did not affect EXT. When the effects of insulin and IGF-I on HR and EXT immunoreactive mass were examined, only HR mass was affected. The doseresponse curve for insulin on HR mass is shown in Fig. 8. As can be seen, a high concentration of insulin stimulated HR immunoreactive mass to the same extent that it stimulated HR catalytic activity (11). Thus, insulin and IGF-I stimulate increases in HR immunoreactive mass that coincide with the increase in HR activity.

The effects of $10 \%$ fetal bovine serum on HR and EXT are shown in Fig. 9. As with IGF-I, there were increases in HR activity and HR immunoreactive mass, such that there was no change in HR specific activity. With EXT, however, there was a significant increase in EXT immunoreactive mass in the face of no change in EXT activity, resulting in a decrease in EXT

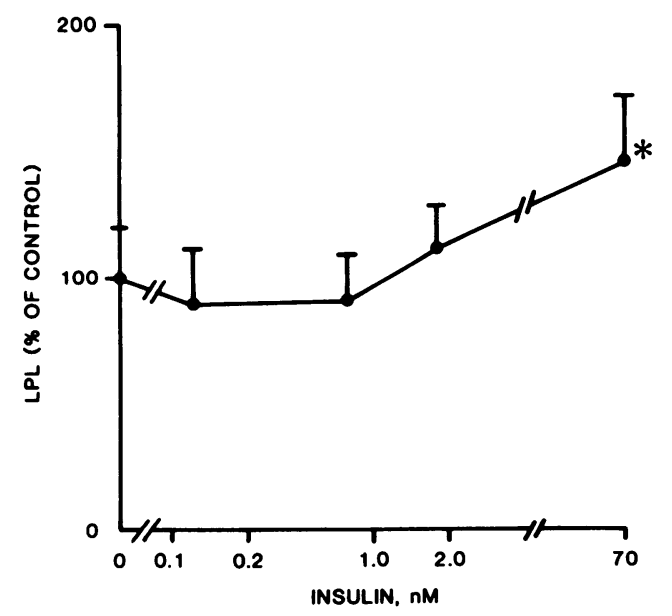

Figure 8. Effect of insulin on LPL immunoreactive mass. Adipocytes were cultured for $24 \mathrm{~h}$ in medium containing the indicated concentration of insulin. LPL immunoreactive mass was then determined on the HR fraction. Control HR mass was $67.9 \pm 15(n=13) \mathrm{ng} / 10^{6}$ cells. Each point represents $5-13$ experiments. ${ }^{*} P<0.05$ vs. control.

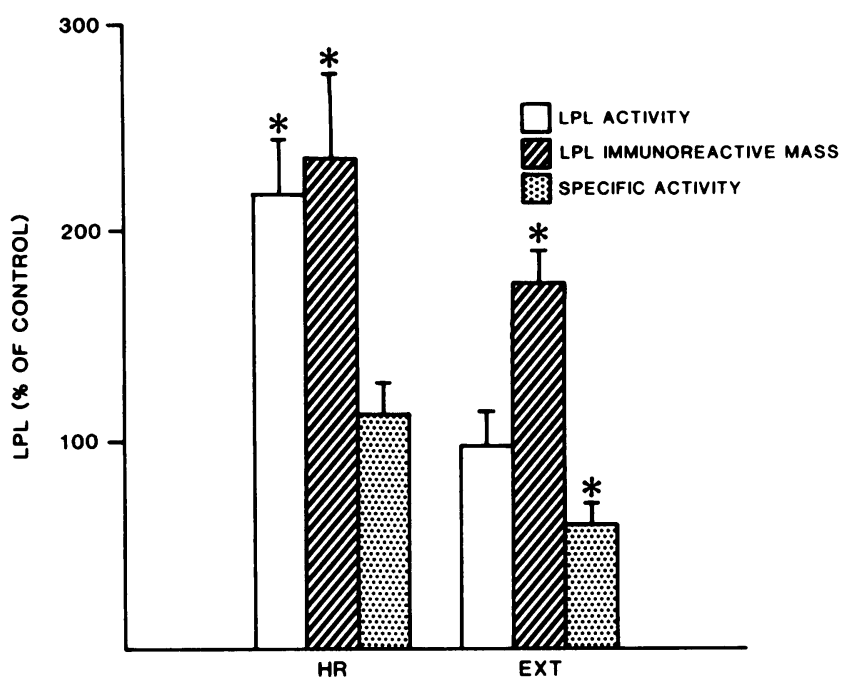

Figure 9. Effect of serum on LPL cellular activity and mass. The HR and EXT fractions were prepared from adipocytes that were cultured in the presence and absence of $10 \%$ fetal bovine serum. LPL activity and immunoreactive mass were measured and specific activity calculated. Data are expressed as a percentage of control, and represent six to nine experiments. ${ }^{*} P<0.05$.

specific activity (Fig. 9). Thus, the presence of $10 \%$ serum results in an increase in the LPL protein that is not accompanied by an increase in LPL activity.

To determine whether adenosine influences human adipocyte LPL, cells were incubated in medium containing a range of concentrations of $\mathrm{N}^{6}$-phenyl-isopropyladenosine (PIA, a nonmetabolizable adenosine analogue). LPL activity and immunoreactive mass were measured after $24 \mathrm{~h}$ as $\mathrm{HR}$ and EXT. As shown in Fig. $10 \mathrm{~A}$, PIA produced a dose-related increase in HR activity, with no effect on EXT activity. Fig. $10 B$ shows the effect of PIA on HR and EXT immunoreactive mass. An increase in HR mass was observed that corresponded to the increase in HR activity. In addition, there was a statistically significant increase in EXT immunoreactive mass at PIA concentrations of 50 and $100 \mathrm{nM}$, even though no increase in EXT activity was observed (Fig. $10 \mathrm{~A}$ ). This resulted in a change in LPL specific activity in EXT. As shown in Fig. 11, there was a statistically significant fall in EXT specific activity, corresponding to the increase in EXT immunoreactive mass with no change in EXT activity, at a PIA concentration of 50 nM. In contrast, PIA had no effect on HR specific activity, since $H R$ activity and immunoreactive mass increased in parallel. Thus, PIA stimulated an increase in the LPL protein content of both the HR and EXT fractions of human adipocytes. However, as with the effect of serum, this increase in LPL protein in EXT was unaccompanied by an increase in LPL activity, resulting in a decreased enzyme specific activity.

Inosine is a metabolite of adenosine that may have independent metabolic effects on adipose tissue (22). To determine whether inosine affected LPL, cells were cultured for $24 \mathrm{~h}$ in the presence of a wide range of concentrations. As shown in Fig. $12 \mathrm{~A}$, inosine stimulated HR activity at approximately the same concentration as did PIA, and this effect diminished at very high concentrations. As with PIA, inosine had no effect on EXT activity. The effect of inosine on LPL immunoreactive mass is shown in Fig. 12 B. An increase in HR mass was 

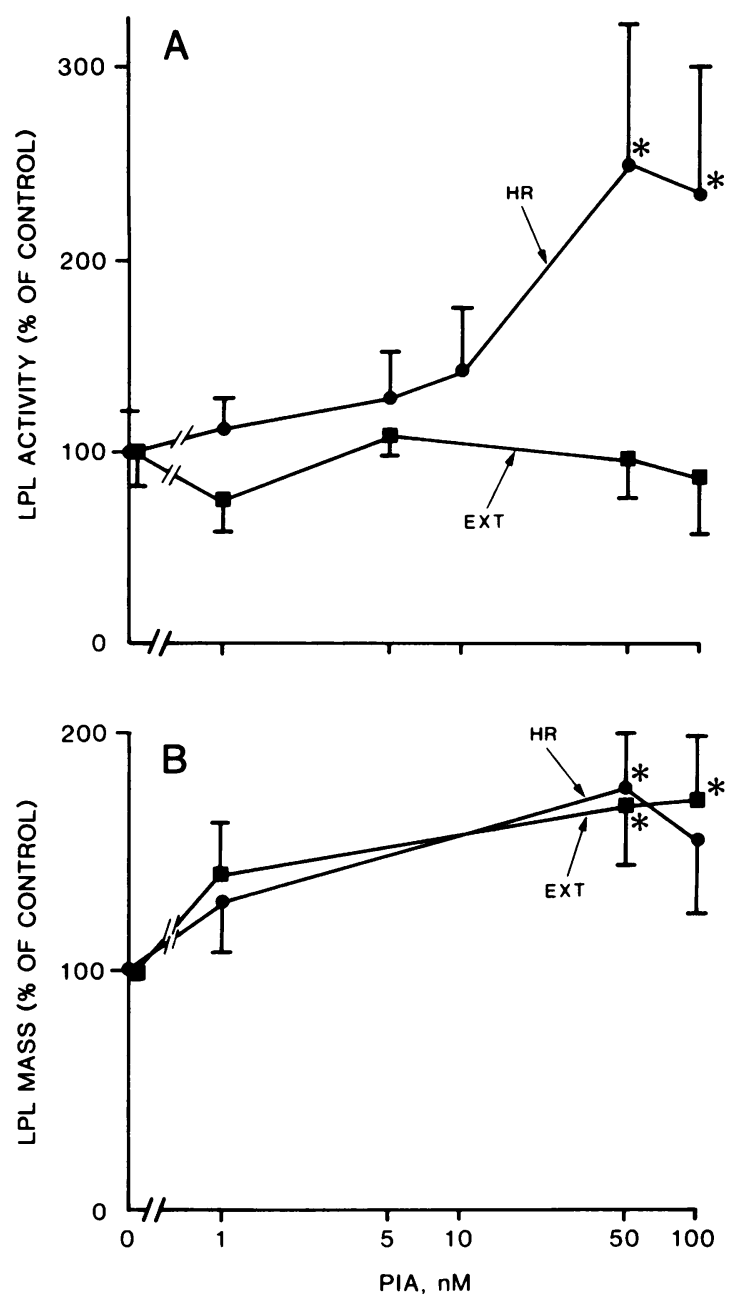

Figure 10. Effect of adenosine on LPL. Cells were cultured for $24 \mathrm{~h}$ in medium containing the indicated concentrations of PIA, the nonmetabolizable analogue of adenosine. Cellular LPL was measured as the HR and EXT fractions (see Methods). ( $A$ ) LPL activity; control HR was $0.40 \pm 0.11(n=8)$ and control EXT was $1.03 \pm 0.23(n=6)$ neq/min per $10^{6}$ cells. $(B)$ LPL immunoreactive mass; control HR was $74.6 \pm 17.1(n=12)$, and control EXT was $107 \pm 44(n=6)$ $\mathrm{ng} / 10^{6}$ cells. Each point represents at least six experiments. ${ }^{*} P<0.05$ vs. control.

observed that paralleled the increase in LPL activity. No effect of inosine was observed on EXT mass, and hence there was no change in LPL specific activity. Hence, the effect of inosine on adipocyte LPL was quantitatively similar to that of PIA, although with inosine, only HR was affected.

In previous studies, adenosine potentiated the effects of insulin on glucose transport and inhibition of lipolysis (16). Although insulin at physiologic concentrations had no effect on LPL, we wondered whether the combined effects of insulin plus PIA or inosine would stimulate LPL to a greater degree than did each substance individually. Therefore, cells were cultured in medium containing insulin at a physiologic concentration $(0.72 \mathrm{nM})$ in the presence of PIA $(50 \mathrm{nM})$ or inosine $\left(10^{-7} \mathrm{M}\right)$. Insulin did not potentiate the effects of PIA or inosine (data not shown). Thus, insulin plus adenosine do not affect LPL in the same manner that they act together to facilitate other aspects of adipocyte metabolism.

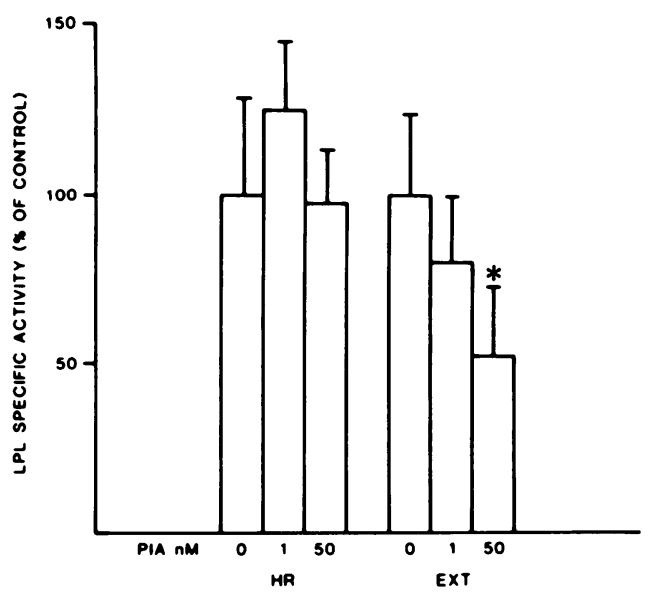

Figure 11. Effect of adenosine on LPL specific activity. Cells were cultured in the indicated concentration of PIA for $24 \mathrm{~h}$ as described for Fig. 9. Control specific activity was $36 \pm 13$ and $43 \pm 15 \mathrm{neq} / \mathrm{min}$ per $\mu \mathrm{g}$ for HR and EXT, respectively. Data are from six experiments. ${ }^{*} P<0.05$ vs. control.

\section{Discussion}

Although the regulation of LPL activity has been the subject of much investigation, the study of the LPL protein has been hindered by difficulties in obtaining a good antibody. Although numerous antisera to LPL have been reported, only a few studies have successfully applied an antibody to the study of LPL regulation. Cheung et al. (23) developed a radioimmunoassay for chicken LPL using a goat anti-LPL antiserum. With this assay, the binding of avian LPL to endothelial cells was characterized (24). Several groups of investigators have used an antibody raised in goats against rat adipose LPL (25) to study the regulation of rat adipose LPL by insulin (10), as well as the development $(26)$ and glycosylation $(27,28)$ of LPL in preadipocytes.

Several studies have reported anti-LPL antibodies that react with human $\operatorname{LPL}(4,5,29-32)$. Using an antibody raised in rabbits against bovine LPL, Jonasson et al. (29) demonstrated positive immunofluorescence in human adipose tissue. Goldberg et al. (5) raised a monoclonal antibody against human milk LPL and then used this antibody to set up an ELISA for postheparin plasma LPL. In addition, Scheibel et al. (33) have reported preliminary data on the use of a monoclonal antibody to study plasma LPL. None of these studies demonstrated quantitation of LPL immunoreactive mass in human adipose tissue. In addition, most studies have not demonstrated antibody specificity for LPL with such sensitive techniques as Western blotting or immunoprecipitation.

The antibody used in this study was raised in chickens against purified bovine LPL and has been successfully applied to an ELISA for rat LPL (20). In addition to reacting with rat LPL, the anti-LPL antisera inhibited LPL activity in human adipocytes. Because of the high degree of homology between bovine and human LPL (34), it is not surprising that this antibody cross-reacts with LPL from rats and humans. Because the antigen (bovine LPL) can be obtained in pure form and in sufficient quantities, the polyclonal antiserum was affinity purified. This process permitted the development of the "sandwich-type" ELISA described herein. 

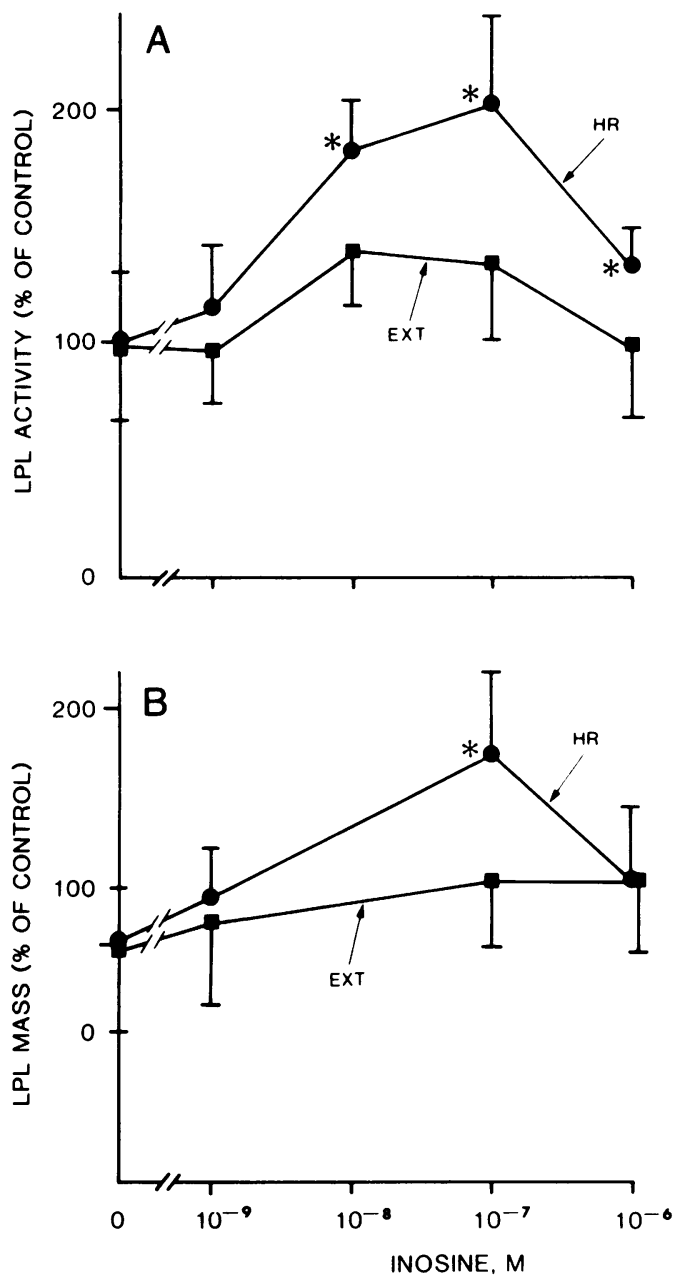

Figure 12. Effect of inosine on LPL activity and immunoreactive mass. Cells were cultured for $24 \mathrm{~h}$ in the indicated concentration of inosine, and then cellular LPL was assessed as HR and EXT. $(A)$ LPL activity; control HR and EXT were $0.86 \pm 0.25$ and $1.36 \pm 0.34$ $\mathrm{neq} / \mathrm{min}$ per $10^{6}$ cells, respectively. $(B)$ LPL immunoreactive mass; control HR and EXT were $70.9 \pm 18.2$ and $106 \pm 44 \mathrm{ng} / 10^{6}$ cells, respectively. Each point represents at least six experiments. ${ }^{*} P<0.05$ vs. control.

The specificity of this antibody for LPL has been demonstrated previously in rat adipocytes (20). For human adipocytes, antibody specificity was demonstrated by Western blotting and immunoprecipitation. The specific anti-LPL antibodies were removed from the antiserum by adsorption on bovine LPL-Sepharose. When Western blotting was performed with the flow-through from this affinity purification step, the 53-kD bands for both bovine LPL and human adipocyte homogenate were not present. Thus, the identity of the 53-kD bands as LPL was proved. In a similar fashion, the competition for radiolabeled LPL by bovine LPL during immunoprecipitation demonstrated that the 53-kD band was LPL. Thus, this antibody is specific for LPL in human adipocytes.

When prepared with protease inhibitors, LPL in adipose tissue and adipocytes was represented by a single band that comigrated with bovine LPL at an apparent molecular mass of $53 \mathrm{kD}$. In the absence of protease inhibitors, breakdown products were observed at molecular mass of 35 and $20 \mathrm{kD}$. Studies by other investigators have also described LPL degradation products of similar size $(35,36)$. Previous studies have reported a variety of subunit molecular mass for LPL on SDSPAGE (reviewed in references 1-3). In recent studies, the complete amino acid sequence of human LPL (34) from the human cDNA has suggested an unglycosylated molecular mass of 50,394 daltons. Therefore, the molecular mass reported herein is appropriate. Minor differences in molecular mass between our studies and those of others are probably due to variations in gel conditions or molecular mass standards.

The ELISA for human LPL was performed essentially as described previously for rat LPL (20). Because purified human LPL was not available as a standard in the ELISA, bovine LPL was used. Although it is possible that the antibodies recognize human LPL in a manner different from bovine LPL, the standard curves for bovine LPL and human adipose tissue LPL were parallel. In addition, a serial dilution of human adipose tissue yielded a parallel decrease in LPL activity and immunoreactive mass. Thus, the bovine LPL standard curve permits an accurate estimation of the human LPL protein.

Previous studies in isolated human adipocytes have characterized the response of LPL activity to IGF-I and insulin (11). When both LPL activity and immunoreactive mass were measured in cells cultured in IGF-I or insulin (Fig. 7), LPL immunoreactive mass increased in response to IGF-I, and did not change in response to a moderately high insulin concentration $(1.8 \mathrm{nM})$. To further examine the effect of insulin on adipocyte LPL, cells were exposed to insulin over a wide range of concentrations (Fig. 8). Again, no effect of insulin was seen on LPL, except at a very high concentration $(70 \mathrm{nM})$. This effect of high insulin concentrations may be due to cross-reactivity of insulin with IGF-I receptors (37). Thus, under these conditions, LPL immunoreactive mass increased along with LPL activity, resulting in no change in enzyme specific activity.

LPL activity has been shown to be low during states of insulin deficiency, such as during fasting (38), and in insulindeficient patients with diabetes (39). In addition, LPL increased after a meal (40), after treatment of diabetic humans with insulin (39), and after an insulin-glucose infusion in normal subjects $(41,42)$. In vitro studies, however, have failed to observe an increase in LPL activity in whole adipose tissue (12) or isolated adipocytes (11) in response to physiologic concentrations of insulin. Thus, these data suggest that the increase in LPL during a hyperinsulinemic state is not a direct effect of insulin, but instead is related to secondary effects of insulin.

The increase in cellular LPL activity with a high insulin concentration and IGF-I was confined to the HR fraction (11). When LPL immunoreactive mass was examined in response to these stimuli, an increase in HR mass was observed that paralleled the increase in HR activity. However, insulin and IGF-I had no effect on EXT activity or mass. In contrast, serum stimulated EXT immunoreactive mass even though there was no effect on EXT activity, resulting in a decreased specific activity of the EXT enzyme. Thus, these data suggest that serum stimulates LPL via a different mechanism than that of insulin and IGF-I. Alternatively, serum may contain a number of different substances each of which affects LPL at a different site of enzyme synthesis.

Adenosine has been shown previously to be a locally produced regulator of adipose tissue metabolism $(14,15)$. In ad- 
dition to being a vasodilator in many tissues, adenosine potentiated insulin action and inhibited lipolysis in adipose tissue (16). Adenosine, and its nonmetabolizable analogue PIA, react with the $\mathbf{R}$ site, which is an outer plasma membrane receptor $(14,43)$. Inosine is a metabolite of adenosine which reacts with the $P$ site, which is an inner plasma membrane receptor. Several studies have suggested that adenosine may be a regulator of LPL. When rats were injected with PIA, there was an increase in adipose tissue and postheparin plasma LPL activity (44). Attempts to reproduce this effect of PIA in vitro, however, have been contradictory. Two studies have reported either an increase (45) or no change (22) in rat fat pad LPL in response to PIA, whereas inosine stimulated LPL in one of these studies (22).

To study the effect of adenosine on human adipocyte LPL, cells were cultured in medium containing a wide range of concentrations of the adenosine analogue PIA. PIA produced a dose-related increase in both HR activity and immunoreactive mass. Because both HR activity and mass increased, there was no change in enzyme specific activity. In contrast, EXT immunoreactive mass increased in response to PIA, even though EXT activity did not change. Thus, PIA decreased the specific activity of the EXT enzyme.

There are several possible explanations for this change in EXT specific activity. PIA may stimulate an increase in LPL protein synthesis. If, however, other factors are necessary for optimal posttranslational processing, then much of this newly synthesized protein may remain unprocessed, and therefore would probably be inactive. Studies in preadipocytes have suggested the existence of an inactive, incompletely processed form of LPL (26). An inactive LPL protein would probably be detected by the ELISA, thus leading to an overall decrease in EXT specific activity. Alternatively, PIA may inhibit breakdown of newly synthesized (and inactive) LPL, such that the mass of LPL protein increased, yet the activity of the EXT pool remained the same.

When inosine was added to adipocyte cultures, cellular LPL increased to a similar degree as with PIA. However, inosine only increased HR activity and mass, and had no effect on EXT. Thus, inosine affected adipocyte LPL in a manner similar to that of high insulin concentrations and IGF-I. Because PIA and inosine function through different receptors, it is indeed possible that each nucleoside has a different mechanism of action, and hence increase different components of cellular LPL.

The regulation of LPL by adenosine may be of physiologic significance, and may explain some of the differences between the regulation of rat and human LPL. Human adipocyte LPL is relatively unresponsive to insulin in vitro, yet is responsive to adenosine, which potentiates the insulin effect in other tissues. On the other hand, rat adipocytes are sensitive to insulin (9), and only variably responsive to adenosine $(22,45,46)$. Thus, human adipocyte LPL may be more responsive to locally produced substances, such as adenosine, whereas rat adipose LPL may be more responsive to humoral stimuli, such as insulin. Further studies need to clarify the regulation of adenosine secretion into the microvasculature.

A mechanism for LPL regulation has been proposed that involves two steps: stimulation of LPL synthesis as a proenzyme, followed by activation of this proenzyme (47). The data described herein are consistent with such a mechanism. Because the HR enzyme is either secreted or released by heparin, it probably represents a more mature form of LPL than the enzyme found in the EXT fraction. Some substances, such as IGF-I, high insulin concentrations, and inosine, exert their regulatory influence only on HR. This may be due to a hormoneinduced facilitation of LPL posttranslational processing, and hence a net movement of LPL protein into a more accessible or secretable cellular compartment. Other substances, such as PIA and serum, increase LPL in both HR and EXT. This latter form of regulation may stem from a predominant influence on new protein synthesis. The increase in EXT protein may be due to the synthesis of an inactive, incompletely processed enzyme, whereas the increase in HR may be due to a secondary effect on LPL processing. More definitive answers to these questions will require further studies of LPL synthesis.

In summary, we have described herein an ELISA for human adipose tissue LPL using a highly specific, affinity-purified, polyclonal antibody. Using this ELISA, human adipose LPL immunoreactive mass has been measured for the first time, and regulation of LPL activity and mass has been demonstrated in response to insulin, IGF-I, serum, the adenosine analogue PIA, and inosine. Further studies with these techniques will permit further characterization of LPL regulation and cellular processing.

\section{Acknowledgments}

We wish to thank the many surgeons in the Departments of Surgery and Obstetrics and Gynecology at Cedars-Sinai Medical Center for their cooperation in obtaining adipose tissue. In addition, we thank Angela Mandic and Robert Martin for excellent technical assistance, and the Cedars-Sinai Medical Center Word-Processing Center for help with the preparation of this manuscript.

This work was supported by a Feasibility Grant from the American Diabetes Association and by grants AM-HL-37085 and HL-30258 from the National Institutes of Health.

\section{References}

1. Garfinkel, A. S., and M. C. Schotz. 1987. Lipoprotein lipase. In Lipoproteins. A. M. Gotto, Jr., editor. Elsevier, Amsterdam. 335-354.

2. Jackson, R. L. 1983. Lipoprotein lipase and hepatic lipase. In The Enzymes. Vol. 16. P. D. Boyer, editor. Academic Press, Inc., New York. 141-181.

3. Nilsson-Ehle, P., A. S. Garfinkel, and M. C. Schotz. 1980. Lipolytic enzymes and plasma lipoprotein metabolism. Annu. Rev. Biochem. 49:667-693.

4. Olivecrona, T., and G. Bengtsson. 1983. Immunochemical properties of lipoprotein lipase. Development of an immunoassay applicable to several mammalian species. Biochim. Biophys. Acta. 752:38-45.

5. Goldberg, I. J., J. R. Paterniti, Jr., D. S. France, G. Martinelli, and J. A. Cornicelli. 1986. Production and use of an inhibitory monoclonal antibody to human lipoprotein lipase. Biochim. Biophys. Acta. 878:168-176.

6. Pykalisto, O. J., P. H. Smith, and J. D. Brunzell. 1975. Determinants of human adipose tissue lipoprotein lipase. Effects of diabetes and obesity on basal- and diet-induced activity. J. Clin. Invest. 56:1108-1117.

7. Taskinen, M.-R., and E. A. Nikkila. 1979. Lipoprotein lipase activity of adipose tissue and skeletal muscle in insulin-deficient human diabetes. Relation to high-density and very-low-density lipoproteins and response to treatment. Diabetologia. 17:351-356.

8. Brunzell, J. D., R. S. Schwartz, R. H. Eckel, and A. P. Goldberg. 1981. Insulin and adipose tissue lipoprotein lipase in humans. Int. J. Obes. 5:685-694. 
9. Eckel, R. H., J. E. Prasad, P. A. Kern, and S. Marshall. 1984. Insulin regulation of adipose tissue lipoprotein lipase in cultured rat adipocytes. Endocrinology. 114:1665-71.

10. Vydelingum, N., R. L. Drake, J. Etienne, and A. H. Kissebah. 1983. Insulin regulation of fat cell ribosomes, protein synthesis, and lipoprotein lipase. Am. J. Physiol. 245:E121-E131.

11. Kern, P. A., S. Marshall, and R. H. Eckel. 1985. Regulation of lipoprotein lipase in primary cultures of isolated human adipocytes. $J$. Clin. Invest. 75:199-208.

12. Elkeles, R. S. 1974. Lipoprotein lipase in human adipose tissue. Clin. Sci. Mol. Med. 46:753-762.

13. Kern, P. A., A. Mandic, and R. H. Eckel. 1987. Regulation of lipoprotein lipase by glucose in primary cultures of isolated human adipocytes: relevance to the hypertriglyceridemia of diabetes. Diabetes. 36:1238-1245.

14. Arch, J. R. S., and E. A. Newsholme. 1979. The control of the metabolism and the hormonal role of adenosine. Essays Biochem. 14:82-123.

15. Fredholm, B. B. 1981. Adenosine and lipolysis. Int. J. Obes. 5:643-649.

16. Schwabe, U., P. S. Schonhofer, and R. Ebert. 1974. Facilitation by adenosine of the action of insulin on the accumulation of adenosine $3^{\prime}: 5$ '-monophosphate, lipolysis, and glucose oxidation in isolated fat cells. Eur. J. Biochem. 46:537-545.

17. Paten, R. L. 1970. The reciprocal regulation of lipoprotein lipase activity and hormone-sensitive lipase activity in rat adipocytes. J. Biol. Chem. 245:5577-85.

18. Iverius, P.-H., and A. M. Ostlund-Lindqvist. 1986. Preparation, characterization, and measurement of lipoprotein lipase. Methods Enzymol. 129:691-716.

19. Belfrage, P., and M. Vaughn. 1969. Simple liquid-liquid partition system for isolation of labeled oleic acid from mixture with glycerides. J. Lipid Res. 10:341-344.

20. Goers, J. W. F., M. F. Petersen, P. A. Kern, J. Ong, and M. C. Schotz. 1987. An enzyme-linked immunoassay for lipoprotein lipase. Anal. Biochem. 166:27-35.

21. Chamberlain, J. P. 1979. Fluorographic detection of radioactivity in polyacrylamide gels with the water-soluble fluor, sodium salicylate. Anal. Biochem. 98:132-135.

22. Bourdeaux, A.-M., M.-C. Rebourcet, J. Nordmann, R. Nordmann, and Y. Giudicelli. 1982. Rat adipocyte lipoprotein lipase activity is inhibited by theophylline and stimulated by inosine through adenosine-independent mechanisms. Biochem. Biophys. Res. Commun. 107:59-67.

23. Cheung, A. H., A. Bensadoun, and C.-F. Cheng. 1979. Direct solid phase radioimmunoassay for chicken lipoprotein lipase. Anal. Biochem. 94:346-357.

24. Cheng, C.-F., G. M. Oosta, A. Bensadoun, and R. D. Rosenberg. 1981. Binding of lipoprotein lipase to endothelial cells in culture. J. Biol. Chem. 256:12893-12898.

25. Etienne, J., L. Noe, M. Rossignol, C. Arnaud, N. Vydelingum, and A. H. Kissebah. 1985. Antibody against rat adipose tissue lipoprotein lipase. Biochim. Biophys. Acta. 834:95-102.

26. Vannier, C., E.-Z. Amri, J. Etienne, R. Negrel, and G. Ailhaud. 1985. Maturation and secretion of lipoprotein lipase in cultured adipose cells. I. Intracellular activation of the enzyme. J. Biol. Chem. 260:4424-4431.

27. Amri, E.-Z., C. Vannier, J. Etienne, and G. Ailhaud. 1986. Maturation and secretion of lipoprotein lipase in cultured adipose cells. II. Effects of tunicamycin on activation and secretion of the enzyme. Biochim. Biophys. Acta. 875:334-343.

28. Chajek-Shaul, T., G. Friedman, H. Knobler, O. Stein, J. Etienne, and Y. Stein. 1985. Importance of the different steps of glycosylation for the activity and secretion of lipoprotein lipase in rat preadipocytes studied with monensin and tunicamycin. Biochim. Biophys. Acta. 837:123-134.

29. Jonasson, L., G. K. Hansson, G. Bondjers, G. Bengtsson, and
T. Olivercrona. 1984. Immunohistochemical localization of lipoprotein lipase in human adipose tissue. Atherosclerosis. 51:313-326.

30. Shirai, K., D. A. Wisner, J. D. Johnson, L. S. Srivastava, and R. L. Jackson. 1982. Immunological studies on bovine milk lipoprotein lipase. Effects of $\mathrm{f}_{\mathrm{ab}}$ fragments on enzyme activity. Biochim. Biophys. Acta. 712:10-20.

31. Hernell, O., T. Egelrud, and T. Olivecrona. 1975. Serum-stimulated lipases (lipoprotein lipases). Immunological crossreaction between the bovine and the human enzymes. Biochim. Biophys. Acta. 381:233-241.

32. Goldberg, I. J., W. S. Blaner, and D. S. Goodman. 1986. Immunologic and enzymatic comparisons between human and bovine lipoprotein lipase. Arch. Biochem. Biophys. 244:580-584.

33. Scheibel, M., P. Iverius, J. Brunzell, and W. Fujimoto. 1985. Measurement of human lipoprotein lipase (LPL) by enzyme-linked immunosorbent assay (ELISA) using a single monoclonal antibody. Fed. Proc. 44:1156. (Abstr.)

34. Wion, K. L., T. G. Kirchgessner, A. J. Lusis, M. C. Schotz, and R. M. Lawn. 1987. Human lipoprotein lipase complementary DNA sequence. Science (Wash. DC). 235:1638-41.

35. Socorro, L., and R. L. Jackson. 1985. Monoclonal antibodies to bovine milk lipoprotein lipase. Evidence for proteolytic degradation of the native enzyme. J. Biol. Chem. 260:6324-6328.

36. Vydelingum, N. A., F. AlQuadan, A. H. Kissebah, and J. Etienne. 1986. Characterization of rat adipose tissue lipoprotein lipase using a monospecific antibody. Biochim. Biophys. Acta. 876:399-42.

37. Nissley, S. P., and M. M. Rechler. 1984. Somatomedin/insulin-like growth factor tissue receptors. Clin. Endocrinol. Metab. 13:43-67.

38. Persson, B., B. Hood, and G. Angervall. 1970. Effects of prolonged fast on lipoprotein lipase activity eluted from human adipose tissue. Acta Med. Scand. 188:225-230.

39. Taskinen, M.-R., and E. A. Nikkila. 1979. Lipoprotein lipase activity of adipose tissue and skeletal muscle in insulin-deficient human diabetes. Relation to high-density and very-low-density lipoprotein and response to treatment. Diabetologia. 17:351-356.

40. Nilsson-Ehle, P., S. Carlstrom, and P. Belfrage. 1975. Rapid effects on lipoprotein lipase activity in adipose tissue of humans after carbohydrate and lipid intake. Time course and relation to plasma glycerol, triglyceride, insulin levels. Scan. J. Clin. Lab. Invest. 35:373378 .

41. Sadur, C. N., and R. H. Eckel. 1982. Insulin stimulation of adipose tissue lipoprotein lipase: Use of the euglycemic clamp technique. J. Clin. Invest. 69:1119-1125.

42. Yki-Jarvinen, H., M-R. Taskinen, V. A. Koivisto, and E. A. Nikkila. 1984. Response of adipose tissue lipoprotein lipase activity and serum lipoproteins to acute hyperinsulinemia in man. Diabetologia. 26:364-369.

43. Londos, C., and J. Wolff. 1977. Two distinct adenosine-sensitive sites on adenylate cyclase. Proc. Natl. Acad. Sci. USA. 74:54825486.

44. Ohisalo, J. J., H. Strandberg, E. Kostiainen, T. Kuusi, and C. Ehnholm. 1981. Stimulation of lipoprotein lipase activity of rat adipose tissue and post-heparin plasma by $\mathrm{N}^{6}$-(phenylisopropyl)adenosine. FEBS (Fed. Eur. Biochem. Soc.) Lett. 132:121-123.

45. Bourdeaux, A.-M., R. Nordmann, and Y. Giudicelli. 1984. Stimulatory effects of adenosine, adenosine analogs and insulin on adipose tissue lipoprotein lipase activity and their prevention by phosphodiesterase inhibitors. FEBS (Fed. Eur. Biochem. Soc.) Lett. 178:132-136.

46. Eckel, R. H. 1987. Adipose tissue lipoprotein lipase. In Lipoprotein Lipase. J. Borensztajn, editor. Evener Publishers, Inc., Chicago. 79-132.

47. Parkin, S. M., K. Walker, P. Ashby, and D. S. Robinson. 1980. Effects of glucose and insulin on the activation of lipoprotein lipase and on protein synthesis in rat adipose tissue. Biochem. J. 188:193199. 